\title{
Salt- and pH-Resisting Collagen-based Highly Porous Hydrogel
}

\author{
By Ali PourJaVAdI, ${ }^{*}$ Mehran KURDTABaR, and Hossein GHASEMZADEH
}

\begin{abstract}
A novel approach was developed to prepare a highly porous hydrogel with superior salt- and pH-resisting properties. According to this method, synthetic comonomers, i.e. acrylic acid (AA) and 2-acrylamido-2-methylpropanesulfonic acid (AMPS), were polymerized and crosslinked in the presence of hydrolyzed collagen as a natural backbone. The characterizations of hydrogels were investigated by swelling experiment, Fourier transform infrared (FT-IR) spectroscopy, acid-base titration and thermogravimetric analysis (TGA). Morphology of the samples was examined by scanning electron microscopy (SEM). Experimental results indicate that the hydrogel has an absorbency of 360 and $73-82 \mathrm{~g} / \mathrm{g}$ for distilled water and saline solutions, respectively. Water absorbency slightly changes from pH 3 to 8 and interestingly is more than of that in distilled water $(\sim 500 \mathrm{~g} / \mathrm{g})$. The hydrogel thus prepared was showing a better salt- and $\mathrm{pH}$-resistance compared to collagen-g-PAA hydrogel due to the introduction of the AMPS segment and therefore is a suitable candidate for horticulture and tissue engineering applications.
\end{abstract}

KEY WORDS: Hydrolyzed Collagen / Hydrogel / Porous / Salt-resisting / pH-Resisting /

Hydrogels are an important class of materials have been attracting in many industrial applications because of their response to changing environment conditions such as temperature, ${ }^{1} \mathrm{pH}^{2}$ and solvent composition. ${ }^{3}$ Although their attraction in medical and mechanical engineering fields, the technological success of these applications is today limited by their low efficiency and slow rate of response to external stimuli. These are related to the degree of porosity which plays the multiple role of enhancing the total water sorption capability and the rate of response by reducing the transport resistance. ${ }^{4,5}$ Therefore, creation of porosity in hydrogels has been considered as an important process in many ways. ${ }^{6-8}$ According to our prior works, ${ }^{9,10}$ neutralization of the grafted polymer after gel formation or gas releasing during hydrolyzation create a hydrogel with porous structure.

It is desired to develop hydrogels having enhanced absorbency in saline solutions, in various values of $\mathrm{pH}$ and good strength of the swollen gel (high absorbency under load), since the requirements of such applications as long-term water holding in horticulture and hygienic products, and the like. So that there have already several studies focusing on improving some hydrogel properties, and further more some modification method seemed effective. ${ }^{11-14}$ On the basis of our former researches, ${ }^{9,15}$ we have been interested in preparing a hydrogel which possess relatively high water absorbency under certain load and at atmosphere pressure in salt solution.

Natural-based hydrogels have attracted in medical and pharmaceutical interests since their non-toxicity, biocompatibility and biodegradability. This paper describes the preparation and characterization of a partially neutralized collagen- $g$ poly(AA-co-AMPS) porous hydrogel, as a new natural-based polymer, which shows salt- and $\mathrm{pH}$-resisting property. The porous structure has just achieved by partially neutralizing the grafted polymer after gel formation. Morphology studies were shown that the pores were induced into the gel by water evaporation resulting from neutralization heat. The effect of reaction variables affecting the water absorbency of the hydrogel and swelling behavior in various salt and $\mathrm{pH}$ solutions was investigated. Interestingly, water absorbency slightly changes from $\mathrm{pH} 3$ to 8 and is more than of that in distilled water $(\sim 500 \mathrm{~g} / \mathrm{g})$. The absorbency under load (AUL) of optimized hydrogel was determined by using an AUL tester in various applied pressures and also the time dependence of the water retention capacity (WRC) was studied. The hydrogel thus prepared was capable of absorbing water in $\mathrm{NaCl}$ solution 75 and $37 \mathrm{~g} / \mathrm{g}$ at atmosphere pressure and under load (6205 Pa), respectively.

\section{EXPERIMENTAL}

\section{Materials}

Hydrolyzed collagen (Parvar Novin-E Tehran Co., $M_{\mathrm{w}}=$ 2000 to $20000 \mathrm{Da}$ ) was industrial grade which is available in market and it has near $25 \%$ insoluble phosphate salt. $\mathrm{N}, \mathrm{N}^{\prime}$ methylene bisacrylamide (MBA) and ammunium persulfate (Fluka), AA and AMPS (Merk) were used without further purification. All other chemicals were also analytical grade.

\section{Preparation of Hydrogel}

The amounts of the starting materials used for all the different series of the experiments are summarized in Table I. As a general procedure, hydrolyzed collagen (1.33 g) was dissolved in $50 \mathrm{~mL}$ double distilled water and filtered (Whatman 41) to remove its insoluble phosphate salt. Then the solution was added to a three-neck reactor equipped with a mechanical stirrer (Heidolph RZR 2021, three blade propeller type, $300 \mathrm{rpm})$. The reactor was immersed in a thermostated water bath preset at a desired temperature $\left(50-90^{\circ} \mathrm{C}\right)$. Then the 
Table I. Amount of reaction contents used in different sample preparations

\begin{tabular}{|c|c|c|c|c|c|c|c|c|}
\hline Entry & $\begin{array}{c}\text { Collagen } \\
\text { (g) }\end{array}$ & $\begin{array}{l}\text { AA } \\
(g)\end{array}$ & $\begin{array}{c}\text { AMPS } \\
\text { (g) }\end{array}$ & $\begin{array}{c}\text { MBA } \\
(g)\end{array}$ & $\begin{array}{c}\text { APS } \\
(\mathrm{g})\end{array}$ & $\begin{array}{c}\mathrm{NaOH} \\
(\mathrm{g})\end{array}$ & $\begin{array}{c}\text { Temperature } \\
\left({ }^{\circ} \mathrm{C}\right)\end{array}$ & $\begin{array}{c}\text { Water } \\
\text { absorbency } \\
(\mathrm{g} / \mathrm{g})\end{array}$ \\
\hline 1 & 1.33 & 2 & 2 & 0.1 & 0.1 & 1.05 & 80 & 257 \\
\hline 2 & 1.33 & 2 & 2 & 0.12 & 0.1 & 1.05 & 80 & 244 \\
\hline 3 & 1.33 & 2 & 2 & 0.14 & 0.1 & 1.05 & 80 & 158 \\
\hline 4 & 1.33 & 2 & 2 & 0.2 & 0.1 & 1.05 & 80 & 145 \\
\hline 5 & 1.33 & 2 & 2 & 0.25 & 0.1 & 1.05 & 80 & 103 \\
\hline 6 & 1.33 & 2 & 2 & 0.1 & 0.02 & 1.05 & 80 & 101 \\
\hline 7 & 1.33 & 2 & 2 & 0.1 & 0.04 & 1.05 & 80 & 184 \\
\hline 8 & 1.33 & 2 & 2 & 0.1 & 0.06 & 1.05 & 80 & 285 \\
\hline 9 & 1.33 & 2 & 2 & 0.1 & 0.1 & 1.05 & 80 & 257 \\
\hline 10 & 1.33 & 2 & 2 & 0.1 & 0.14 & 1.05 & 80 & 165 \\
\hline 11 & 1.33 & 2 & 2 & 0.1 & 0.2 & 1.05 & 80 & 58 \\
\hline 12 & 1.33 & 3.5 & 0.5 & 0.1 & 0.06 & 1.42 & 80 & 183 \\
\hline 13 & 1.33 & 3.34 & 0.66 & 0.1 & 0.06 & 1.39 & 80 & 270 \\
\hline 14 & 1.33 & 3 & 1 & 0.1 & 0.06 & 1.3 & 80 & 293 \\
\hline 15 & 1.33 & 2.5 & 1.5 & 0.1 & 0.06 & 1.18 & 80 & 360 \\
\hline 16 & 1.33 & 2 & 2 & 0.1 & 0.06 & 1.05 & 80 & 285 \\
\hline 17 & 1.33 & 2.5 & 1.5 & 0.1 & 0.06 & 1.18 & 50 & 145 \\
\hline 18 & 1.33 & 2.5 & 1.5 & 0.1 & 0.06 & 1.18 & 60 & 179 \\
\hline 19 & 1.33 & 2.5 & 1.5 & 0.1 & 0.06 & 1.18 & 70 & 219 \\
\hline 20 & 1.33 & 2.5 & 1.5 & 0.1 & 0.06 & 1.18 & 80 & 360 \\
\hline 21 & 1.33 & 2.5 & 1.5 & 0.1 & 0.06 & 1.18 & 85 & 333 \\
\hline 22 & 1.33 & 2.5 & 1.5 & 0.1 & 0.06 & 1.18 & 90 & 146 \\
\hline
\end{tabular}

initiator solution (APS in $5 \mathrm{~mL} \mathrm{H}_{2} \mathrm{O}$ ) was added to the mixture. After stirring for $5 \mathrm{~min}$, certain weight ratio of AMPS/AA (in $10 \mathrm{~mL} \mathrm{H}_{2} \mathrm{O}$ ) and MBA (in $5 \mathrm{~mL} \mathrm{H}_{2} \mathrm{O}$ ) were simultaneously added to the reaction mixture. After $60 \mathrm{~min}$, the certain amount of $1 \mathrm{~N} \mathrm{NaOH}$ solution, depend on comonomers content, was added to neutralize $70 \%$ of grafted polymer. The mixture was immediately stirred vigorously using a spatula for $2 \mathrm{~min}$ and then poured to excess non solvent ethanol $(200 \mathrm{~mL})$ and remained for $3 \mathrm{~h}$ for dewatering. Then the product scissored to small pieces (diameter $\sim 5 \mathrm{~mm}$ ) and again, $100 \mathrm{~mL}$ fresh ethanol was added and the hydrogel was remained for $24 \mathrm{~h}$. Finally, the filtered hydrogel is dried in oven at $60^{\circ} \mathrm{C}$ for $10 \mathrm{~h}$. After grinding, the resulted powder was stored away from moisture, heat and light.

\section{Swelling Measurements Using Tea Bag Method}

The tea bag (i.e. a 100 mesh nylon screen) containing $0.1 \pm 0.001 \mathrm{~g}$ powdered sample was immersed entirely in $200 \mathrm{~mL}$ double distilled water and allowed to soak for $2 \mathrm{~h}$ at room temperature. The sample particle sizes were 40 to 60 meshes $(250-400 \mu \mathrm{m})$. The tea bag was hung up for $15 \mathrm{~min}$ in order to remove the excess solution. The equilibrium swelling (ES) was calculated according to following equation:

$$
E S(g / g)=\frac{W_{s}-W_{d}}{W_{d}}
$$

where $W_{s}$ and $W_{d}$ are the weights of the swollen superabsorbent and the dry sample, respectively.

\section{Instrumental Analysis}

FT-IR spectra of samples were taken in $\mathrm{KBr}$ pellets using an ABB Bomem MB-100 FT-IR spectrophotometer. The surface morphology of the gel was examined using scanning electron microscopy (SEM). Dried superabsorbent powder were coated with a thin layer of gold and imaged in a SEM instrument (Leo, $1455 \mathrm{VP}$ ). A simultaneous thermal analyzer (STA-625, Reometric Scientific) was used for thermogravimetric analysis (TGA) of collagen and collagen- $g$-poly(AA-co-AMPS) hydrogel under nitrogen atmosphere. The heating rate was $20^{\circ} \mathrm{C} /$ min. The sample weight taken for TG was $10.0 \mathrm{mg}$.

\section{Acid-base Titration}

Acid-base titration was carried out in a thermostatted water bath at $25^{\circ} \mathrm{C}$. The dried gels were finely dispersed in double distilled water. The titration was then performed with $0.1 \mathrm{M}$ $\mathrm{NaOH}$. Default conditions for the experiment were: a stabilization time of $10 \mathrm{~min}$ for the initial system and a delay time of 5 min between each addition of the titrant. The titration data were collected with a Crison MicropH-2002 equipped with a reference electrode $\mathrm{Ag} / \mathrm{AgCl}$.

\section{Swelling in Various Salt Solutions}

Hydrogel absorbency was evaluated in $0.15 \mathrm{M}$ solutions of $\mathrm{LiCl}, \mathrm{NaCl}, \mathrm{KCl}, \mathrm{CsCl}, \mathrm{MgCl}_{2}, \mathrm{CaCl}_{2}, \mathrm{SrCl}_{2}$, and $\mathrm{BaCl}_{2}$ according to the above method described for swelling measurement in distilled water. In addition, swelling capacity of the hydrogel was measured in different concentration of $\mathrm{NaCl}$, $\mathrm{CaCl}_{2}$, and $\mathrm{AlCl}_{3}$ salt solutions.

\section{Absorbency at Various pH values}

Individual solutions with acidic and basic $\mathrm{pH}$ values were prepared by dilution of $\mathrm{NaOH}(\mathrm{pH} 13.0)$ and $\mathrm{HCl}(\mathrm{pH} 1.0)$ solutions to achieve $\mathrm{pH} \geq 6.0$ and $\mathrm{pH}<6.0$, respectively. The $\mathrm{pH}$ values were precisely checked by a $\mathrm{pH}$-meter (Metrohm/620, accuracy \pm 0.1$)$. Then, $0.5( \pm 0.001) \mathrm{g}$ of the dried hydrogel was used for the swelling measurements according to Eq. 1.

\section{pH-sensitivity}

$\mathrm{PH}$-sensitivity of the hydrogel was investigated in terms of swelling and deswelling of the final product at two basic $(\mathrm{pH} 8.0)$ and acidic $(\mathrm{pH} 2.0)$ solutions of phosphate buffer, respectively. Swelling capacity of the hydrogels at each $\mathrm{pH}$ was measured according to Eq. 1 at consecutive time intervals (30 min).

\section{Swelling Kinetics}

For studying the absorbency rate of the hydrogels, certain amount of samples $(0.1 \pm 0.001 \mathrm{~g})$ with various particle sizes were poured into numbers of weighed tea bags and immersed in $200 \mathrm{~mL}$ distilled water. At consecutive time intervals, the water absorbency of the hydrogels was measured according to the above mentioned method.

\section{Water Retention Capacity (WRC)}

Approximately $20-30 \mathrm{mg}$ of dried superabsorbent with average particle sizes of $325 \mu \mathrm{m}$ were dispersed in $50 \mathrm{~mL}$ of distilled water for $30 \mathrm{~min}$. The swollen particles were placed on 

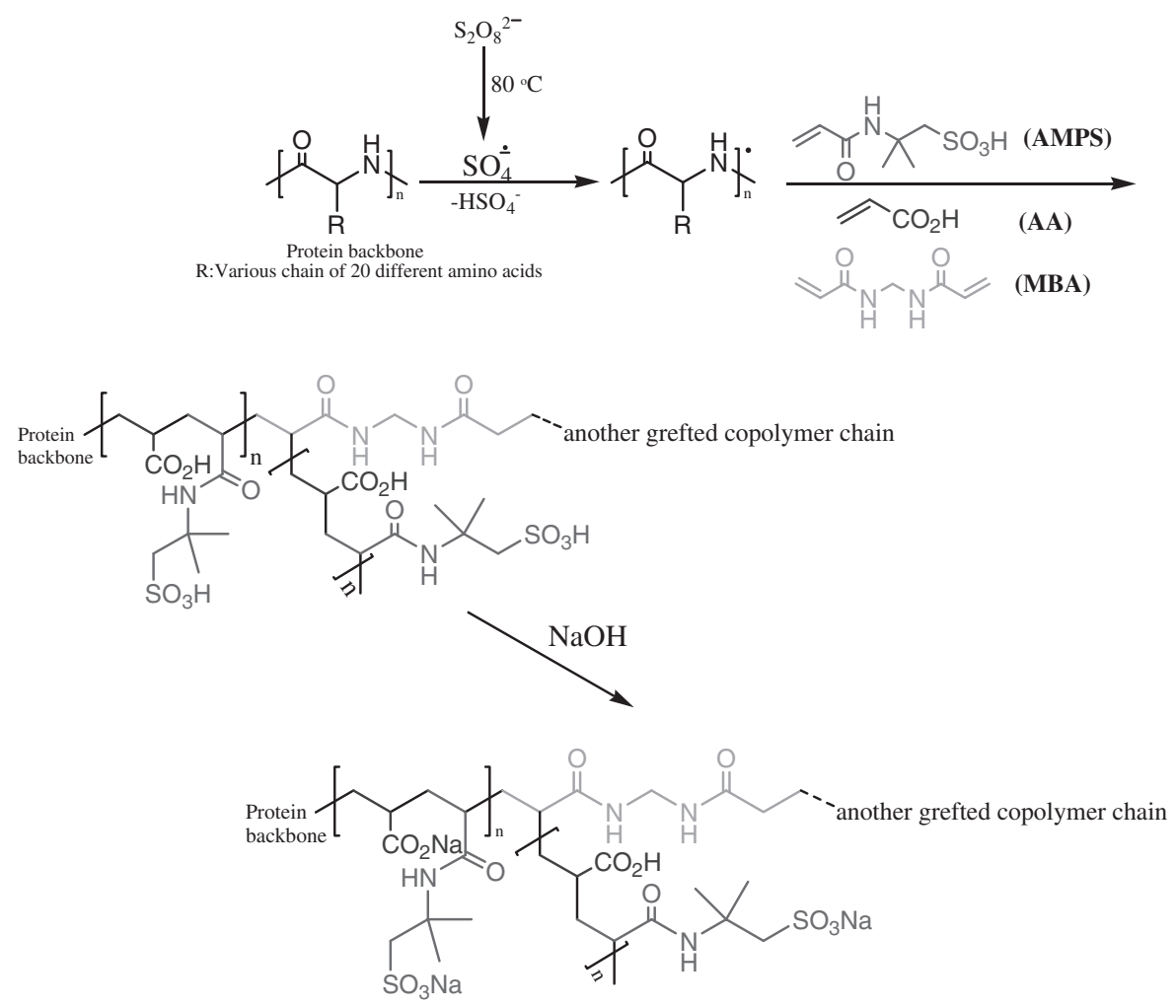

Scheme 1. Proposed mechanistic pathway for synthesis of the partially neutralized collagen-g-poly(AA-co-AMPS) hydrogel.

a gauze fixed in centrifuge tubes, then centrifuged at $2800 \mathrm{rpm}$ at different times, unless otherwise specified, weighed, and centrifuge retention capacity (CRC) was calculated using the above Eq. (1).

For measuring the water retention at constant temperature, the equilibrated gels were drained in 100-mesh nylon bags for $1 \mathrm{~h}$, and then the bags containing the gels were put into a oven through which passed a current of hot dry air at constant temperature $\left(e . g\right.$., 60 or $\left.100^{\circ} \mathrm{C}\right)$. The weights of the bags were measured for every hour in order to investigate the relationship between their weights and the heating time.

\section{Absorbency under Load (AUL)}

A macro-porous sintered glass filter plate (porosity $0, \mathrm{~d}=$ $80 \mathrm{~mm}, \mathrm{~h}=7 \mathrm{~mm})$ was placed in a Petri dish $(\mathrm{d}=118 \mathrm{~mm}$, $\mathrm{h}=12 \mathrm{~mm})$, and weighted dried hydrogel $(0.1 \pm 0.01 \mathrm{~g})$ was uniformly placed on the surface of a polyester gauze located on the sintered glass. A cylindrical solid load (Teflon, $d=60 \mathrm{~mm}$, variable height) is put on the dry hydrogel particles while it can be freely slipped in a glass cylinder $(\mathrm{d}=60 \mathrm{~mm}$, $\mathrm{h}=50 \mathrm{~mm}$ ). Desired load (applied pressure 2068, 4137, and $6205 \mathrm{~Pa}$ ) was placed on the hydrogel sample. Then, $0.9 \%$ saline solution was added so that the liquid level was equal to the height of the sintered glass filter. Whole of the set was covered to prevent surface evaporation and probable change in the saline concentration. After $60 \mathrm{~min}$, the swollen particles were weighted again, and AUL was calculated according to Eq. (1). ${ }^{16}$

\section{Reswelling Capacity}

The sample $(0.05 \mathrm{~g})$ was immersed in a certain milliliter of distilled water to make sure that the swelling equilibrium was achieved. The swollen gel was placed in an oven at $100^{\circ} \mathrm{C}$ until the gel was dried carefully. Then an equal milliliter of water was added to the dried gel and after reaching to the equilibrium, it was placed in the oven again. A similar procedure was repeated and the saturated absorbency of the sample after several times of reswelling was thus obtained.

\section{RESULTS AND DISCUSSION}

\section{Synthesis and Spectral Characterization}

The mechanism for crosslinking graft copolymerization of AMPS/AA comonomers onto collagen backbones in the presence of APS and MBA is shown in Scheme 1. At the first step, the thermally dissociating initiator, i.e. APS, is decomposed under heating $\left(80^{\circ} \mathrm{C}\right)$ to produce sulfate anion-radical. Then the anion-radical abstracts hydrogen from one of the existing functional groups in protein backbone (i.e. $\mathrm{COOH}, \mathrm{SH}$, $\mathrm{OH}$, and $\mathrm{NH}_{2}$ ) to form corresponding macroinitiator. These macroradicals initiate AMPS/AA grafting onto collagen backbone led to a graft copolymer. In addition, in the presence of a crosslinker, i.e., MBA, crosslinking reaction was occurred and finally a three dimensional network was obtained. ${ }^{17,18}$

Infrared spectroscopy was carried out to confirm the chemical structure of the hydrogel. Figure 1 shows the FT-IR spectra of the hydrolyzed collagen and the synthesized hydro- 


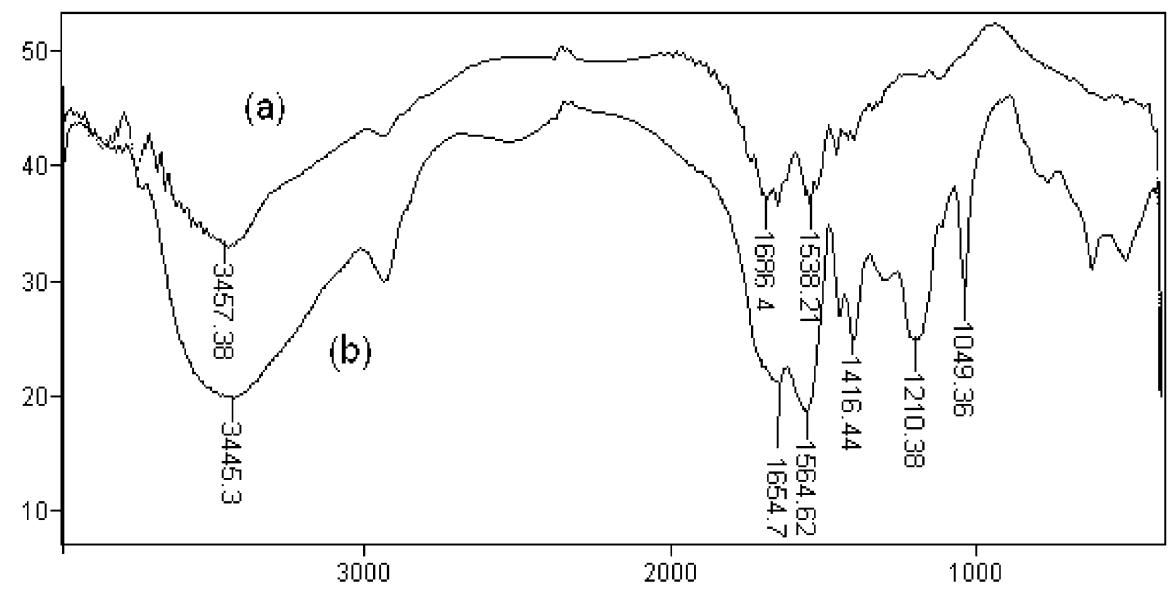

Transmittance/Wavernumber(cm-1)

Figure 1. FT-IR spectra of the hydrolyzed collagen (a) and the partially neutralized collagen-g-poly(AA-co-AMPS) hydrogel (b).

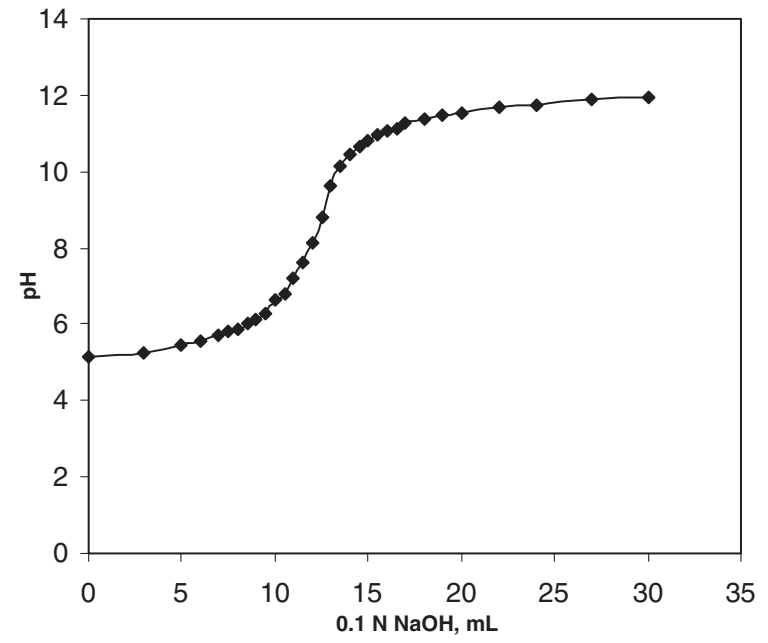

Figure 2. Titration of the partially neutralized collagen- $g$-poly(AA-co-AMPS) hydrogel with $0.1 \mathrm{~N} \mathrm{NaOH}$ solution.

gel. The bands observed at $1686 \mathrm{~cm}^{-1}$ can be attributed to $\mathrm{C}=\mathrm{O}$ stretching in carboxamide functional groups of substrate backbone (Figure 1a). The broad band at $3200-3600 \mathrm{~cm}^{-1}$ is due to stretching of hydroxyl groups of the hydrolyzed collagen. The hydrogel comprises a protein backbone with side chains that carry carboxamide, carboxylate and sulfonate groups which are evidenced by four new characteristic absorption bands at 1049, 1210, 1416 and $1564 \mathrm{~cm}^{-1}$ (Figure 1b). These peaks attributed to symmetric and asymmetric stretching modes of sulfonate and carboxylate anions. ${ }^{19}$

As indicated in Figure 2, the gels were characterized by acid-base titration. The initial $\mathrm{pH}$ of hydrogel was 5.15. This can be related to the remaining free carboxylate groups in the gel body and shown all of the $-\mathrm{SO}_{3} \mathrm{H}$ groups are neutralized. TGA trace is presented in Figure 3. The grafted collagen has shown improvement in thermal stability as clear from TGA curve. The initial decomposition temperature of the collagen on grafting was increased from 321 to $418^{\circ} \mathrm{C}$ with maximum

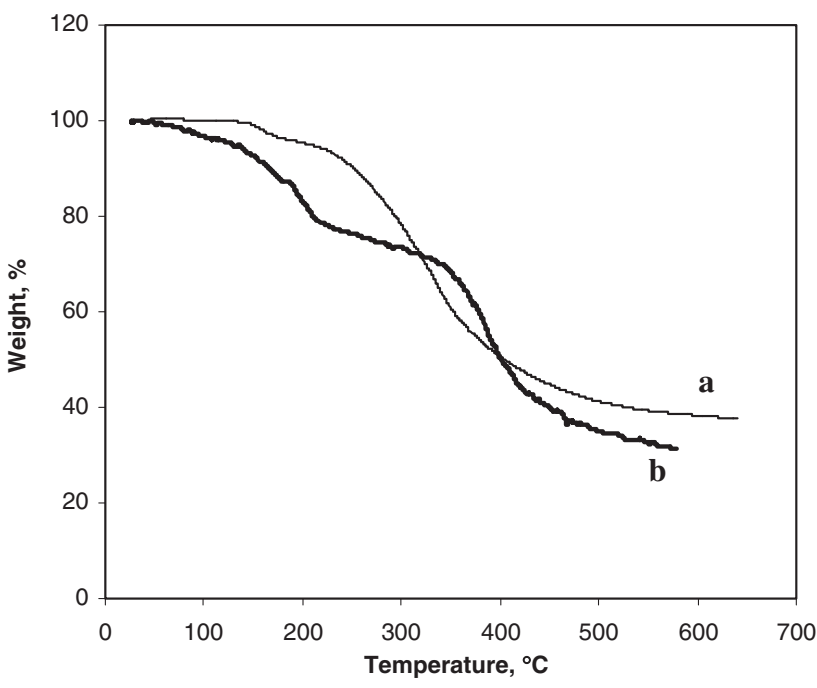

Figure 3. TGA thermograms of the hydrolyzed collagen (a) and the partially neutralized collagen- $g$-poly(AA-co-AMPS) (b) superabsorbent Heating rate $20^{\circ} \mathrm{C} / \mathrm{min}$, under $\mathrm{N}_{2}$.

decomposition rate at $378{ }^{\circ} \mathrm{C}$, in comparison to original decomposition temperature of $320^{\circ} \mathrm{C}$ of collagen. These observations have clearly indicated that grafting of poly(AAco-AMPS) has improved the thermal stability of collagen, and thermal stability was found to be dependent on degree of grafting onto collagen.

\section{Effect of MBA Concentration}

Figure 4 demonstrates the effect of crosslinker concentration on swelling capacity of the product. As shown in Figure 4, increasing the MBA concentration is caused the water absorbency to diminish. More crosslinking concentration reasons to the higher crosslinking density and decreases the spaces between the copolymer chains and consequently, the resulted highly crosslinked rigid structure cannot be expanded and hold a large quantity of water. In fact, in all hydrogels a small increase in degree of crosslinking causes an appreciable 


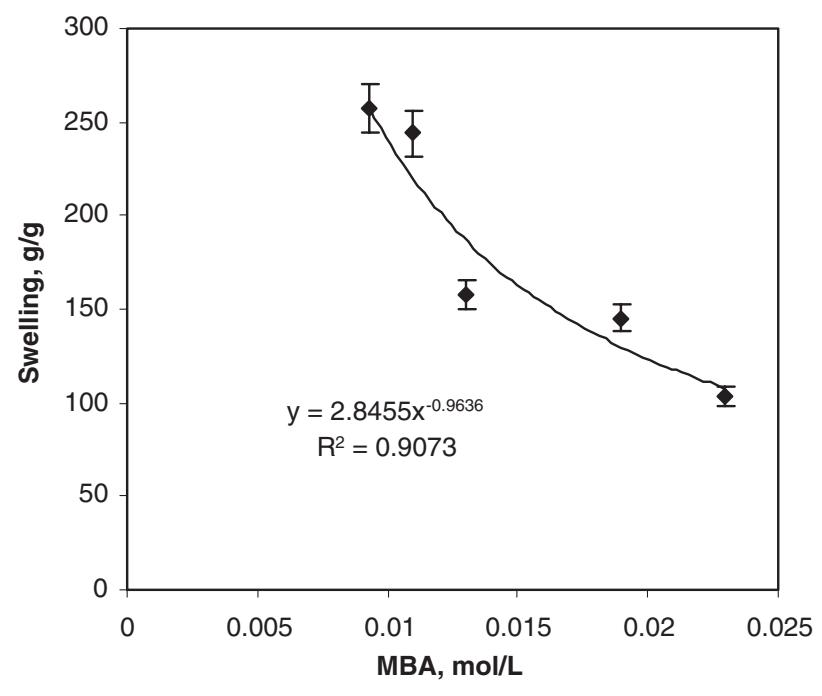

Figure 4. Swelling dependency of the partially neutralized collagen-g-poly(AA-co-AMPS) hydrogel on crosslinker concentration. Reaction conditions: Collagen $1.33 \mathrm{~g}$, AMPS/AA 1 , APS $6.3 \mathrm{mmol} / \mathrm{L}, 80^{\circ} \mathrm{C}$, $60 \mathrm{~min}$.

decrease in swelling capacity. Such well-known behavior was reported by pioneering scientists. ${ }^{20-22}$ Figure 4 exhibits a power law behavior of swelling-[MBA], with $K=2.84$ and $n=0.96$ which is obtained from the curve fitted with Eq. 2.

$$
\text { Swelling capacity } \approx K[\mathrm{MBA}]^{-n}
$$

The $K$ and $n$ are constant values for an individual superabsorbent. The $n$ value represents the sensitivity extent of the hydrogel to the crosslinker content, while the $K$ value gives an amount useful for comparing the extent of swelling versus fixed crosslinker content. According to Figure 4, maximum swelling $(257 \mathrm{~g} / \mathrm{g})$ was obtained at $9.3 \mathrm{mmol} / \mathrm{L}$ of crosslinker concentration so that the hydrogels prepared with MBA concentration lower than $9.3 \mathrm{mmol} / \mathrm{L}$ do not posses good dimensional stability. Therefore the swollen gel strength is not sufficient to refer the hydrogels as "real superabsorbents."

\section{Effect of APS Concentration}

The relationship between the initiator concentration and water absorbency values was studied by varying the APS concentration from 1.2 to $12 \mathrm{mmol} / \mathrm{L}$ (Figure 5). The maximum absorbency $(285 \mathrm{~g} / \mathrm{g})$ is obtained at $3.8 \mathrm{mmol} / \mathrm{L}$ of the initiator. Initial increment in water absorbency maybe attributed to increased number of active free radicals on the protein backbone. Subsequent decrease in swelling is originated from an increase in terminating step reaction via bimolecular collision which, in turn, causes to enhance crosslinking density. This possible phenomenon is referred to as "self crosslinking" by Chen and Zhao. ${ }^{23}$ In addition, the free radical degradation of collagen backbones by sulfate radicalanions is an additional reason for swelling-loss at higher APS concentration. A similar observation is recently reported in the case of polysaccharides such as carrageenan ${ }^{24}$ and chitosan. $^{25}$

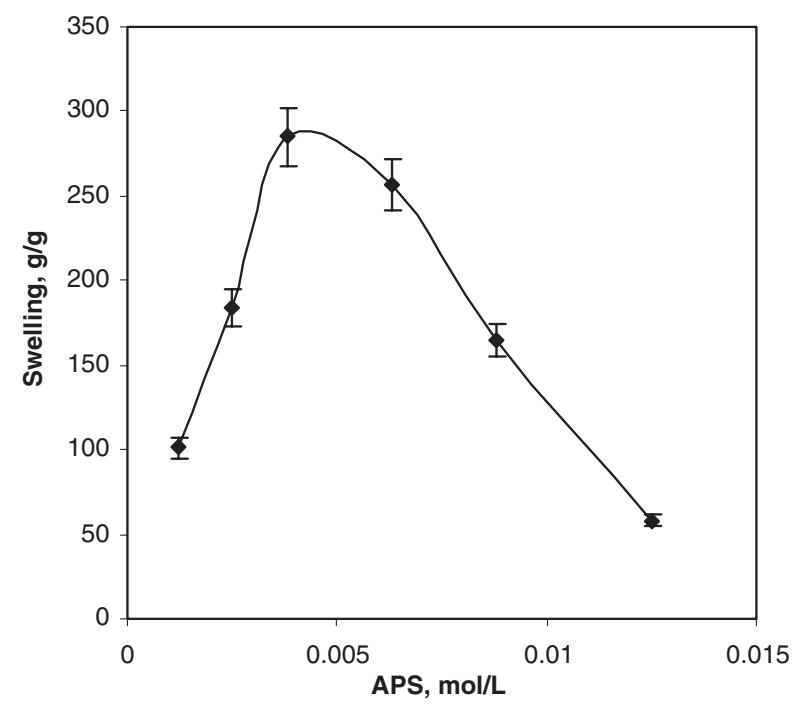

Figure 5. Effect of initiator concentration on swelling capacity of the partially neutralized collagen- $g$-poly(AA-co-AMPS) hydrogel. Reaction conditions: Collagen $1.33 \mathrm{~g}$, AMPS/AA 1 , MBA $9.3 \mathrm{mmol} / \mathrm{L}$, $80^{\circ} \mathrm{C}, 60 \mathrm{~min}$.

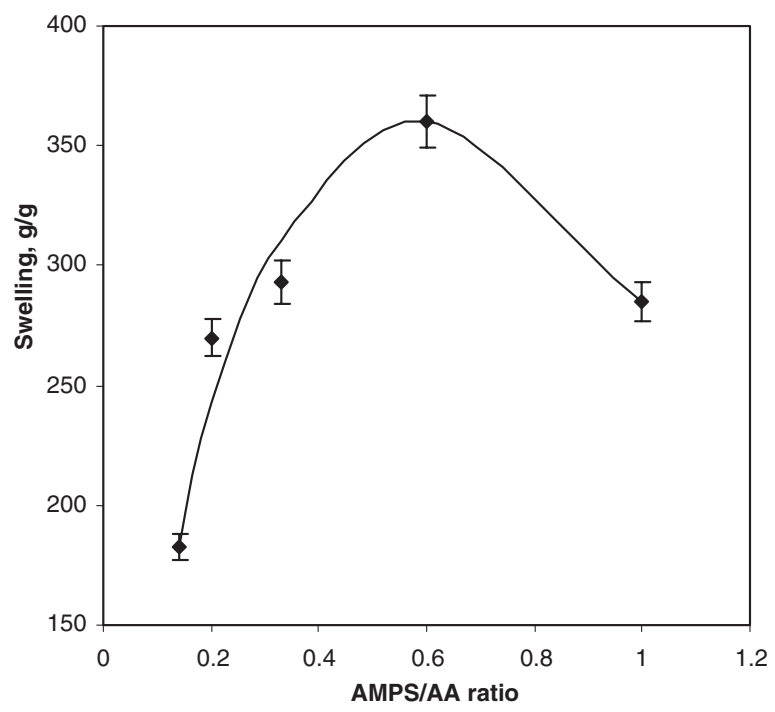

Figure 6. Swelling dependency of the partially neutralized collagen- $g$-poly(AA-co-AMPS) hydrogel as a function of comonomers ratio. Reaction conditions: Collagen $1.33 \mathrm{~g}$, MBA $9.3 \mathrm{mmol} / \mathrm{L}$, APS $3.8 \mathrm{mmol} / \mathrm{L}, 80^{\circ} \mathrm{C}, 60 \mathrm{~min}$

\section{Effect of AMPS/AA Ratio}

The swelling capacity of hydrogel as a function of the comonomers ratio is illustrated in Figure 6. It is observed that the absorbency is substantially increased with increasing in the AMPS/AA ratio and then it is decreased. The initial increment in swelling values can be attributed to decrease repulsive forces between neighboring chains in that the carboxylate group decreased along with increase of AMPS in the gels which allows polymer coils to expand more easily. The swelling-loss after the maximum may be originated from (a) reducing the gel strength due to the higher amount of AMPS, and (b) decrease 


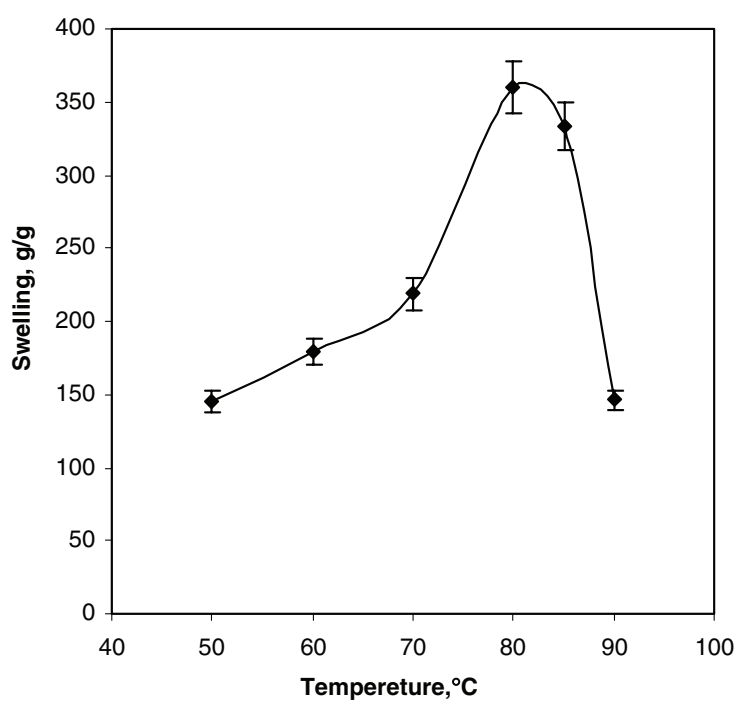

Figure 7. Effect of reaction temperature on swelling capacity. Reaction conditions: Collagen $1.33 \mathrm{~g}$; MBA $9.3 \mathrm{mmol} / \mathrm{L}$; APS $3.8 \mathrm{mmol}$, AMPS/AA 0.6.

in carboxylate groups existing in copolymer chains because of the lower concentrations of AA which declines the osmotic pressure. Similar conclusions were reported by other investigators. $^{26,27}$

\section{Effect of Reaction Temperature}

The swelling capacity of the superabsorbents prepared with various reaction temperatures is shown in Figure 7. Higher temperatures favor the rate of diffusion of AMPS/AA comonomers to the collagen macroradicals and increase the kinetic energy of radical centers. In addition, higher temperatures increase the rate of decomposition of the thermally dissociating initiator, APS. ${ }^{28}$ The temperatures higher than the optimum value $\left(80^{\circ} \mathrm{C}\right)$, however, lead to low-swelling superabsorbents. This swelling loss may be attributed to (a) oxidative degradation of collagen chains by sulfate radicalanions, (b) increasing the rate of termination and chain transfer reactions, and (c) decomposition of APS to give $\mathrm{O}_{2}$ (a radical scavenger), which reacts with primary free radicals, ${ }^{29}$ resulting in decreased molecular weight and decreased swelling (the sulfate radical anions may react with water to produce hydroxyl radicals and finally oxygen).

\section{Swelling in Various Salt Solutions}

Swelling ability of "anionic" hydrogels in various salt solutions is appreciably decreased comparing to the swelling values in distilled water. This well-known undesired swellingloss is often attributed to a "charge screening effect" of the additional cations causing a non-perfect anion-anion electrostatic repulsion. ${ }^{21}$ In addition, in the case of salt solutions with multivalent cations, "ionic crosslinking" at surface of particles causing an appreciably decrease in swelling capacity.

It is obvious that swelling decrease is strongly depended on the "type" and "concentration" of salt added to the swelling

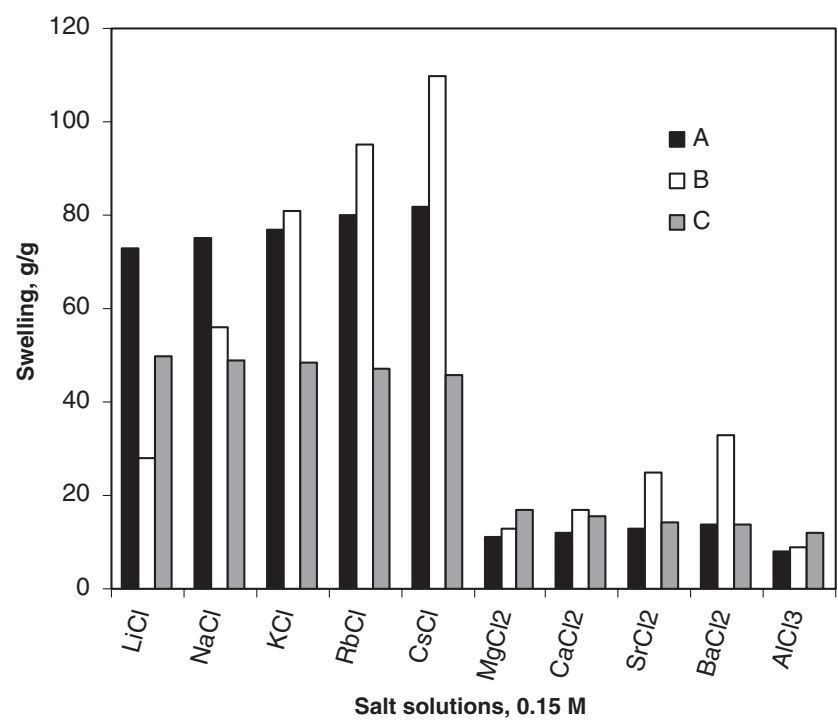

Figure 8. Swelling capacity of the optimized sample (A), collagen-g-PAA (B) and poly(AA-Co-AMPS) (C) in different chloride salt solutions $(0.15 \mathrm{M})$.

medium (Figures 8 and 9). The effect of cation type (cations with different radius and charge) on swelling behavior is shown in Figure 8. With increasing the charge of cation, degree of crosslinking is increased and swelling is consequently decreased. Therefore, the absorbency for the hydrogel in the studied salt solutions is in the order of monovalent $>$ divalent cations $>$ trivalent cations. The effect of cation radius on swelling may also been observed from Figure 8 . As reported by Pass et al. ${ }^{30}$ the carboxylate anion interacts with small cations, e.g. $\mathrm{Li}^{+}$, stronger than with large cations, e.g. $\mathrm{Cs}^{+}$. However, as clear from Figure 8, the change in water absorbency in this hydrogel was slight in each series in comparison with our former works ${ }^{10,15}$ due to the introduction of the AMPS segment. Thus the hydrogel still shows ionic crosslinking in the case of di- and trivalent cations, but its absorbency is slightly depended to cation radius.

As can be seen from Figure 8, poly(AA-co-AMPS) hydrogel shows reverse swelling capacity with increasing the cation radius, in comparison with collagen- $g$-poly(AA-co-AMPS). Formation ionic crosslinks between the sulfate sites of the hydrogel and the large cation is the major responsible for loss of swelling. ${ }^{31}$

Figure 9 illustrates a reverse and power law relationship between concentration of salt solutions $\left(\mathrm{NaCl}, \mathrm{CaCl}_{2}\right.$, and $\mathrm{AlCl}_{3}$ ) and swelling capacity of the hydrogel. Again, charge screening effect and ionic crosslinking are the main explanations for the intense loss of swelling. The known relationship between swelling and concentration of salt solution is stated as following equation: ${ }^{21}$

$$
\text { Swelling }=k[\text { salt }]^{-n}
$$

where $k$ and $n$ are constant values for an individual superabsorbent. The $k$ value is swelling at a high concentration of salt and $n$ value is a measure of salt sensitivity. Figure 9 


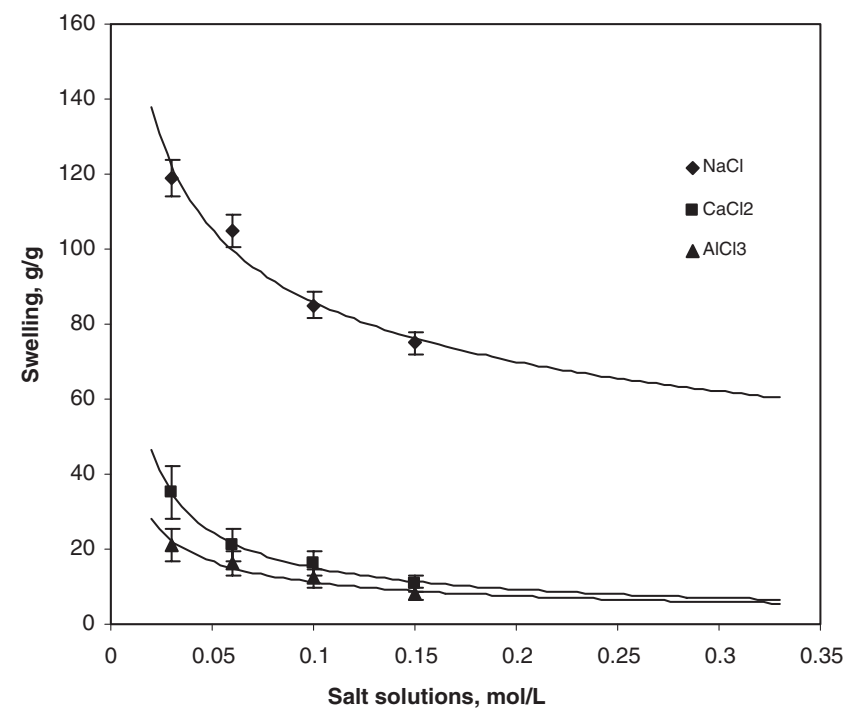

Figure 9. Swelling capacity variation of the optimized sample in saline solutions with various concentrations.

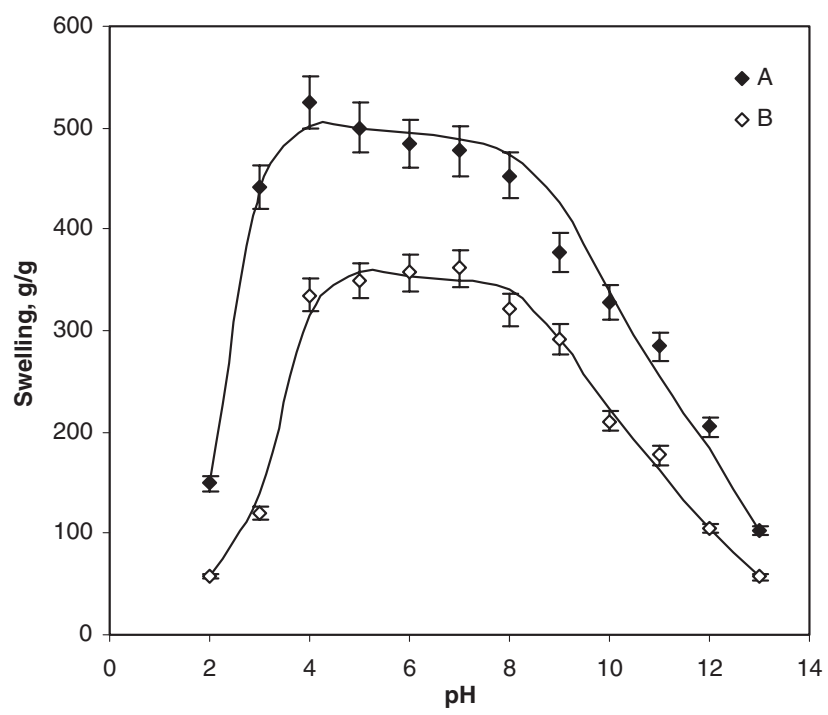

Figure 10. Effect of $\mathrm{pH}$ of solutions on swelling capacity of the optimized sample (A) and poly(AA-co-AMPS) (B).

indicates that changing of the salt concentrations higher than $\sim 0.2 \mathrm{M}$ has no appreciable influence on superabsorbency of the superabsorbent. The $k$ and the $n$ values are proportionally changes with the cation valency enhancement. Here, the effect of the ionic crosslinking acts as more effective factor against swelling rather than the charge screening effect of the cation.

\section{Effect of pH on Equilibrium Swelling}

Since the swelling capacity of all "anionic" hydrogels is appreciably decreased by addition of counter ions (cations), stock $\mathrm{NaOH}(\mathrm{pH} 13.0)$ and $\mathrm{HCl}$ (2.0) solutions were diluted with distilled water to reach desired basic and acidic $\mathrm{pH}$ values, respectively. As shown in Figure 10, the absorbency of the optimized sample increased sharply as the $\mathrm{pH}$ increased from 2 to 3 and drastically decreased in the $\mathrm{pH}$ range of $8-13$. In

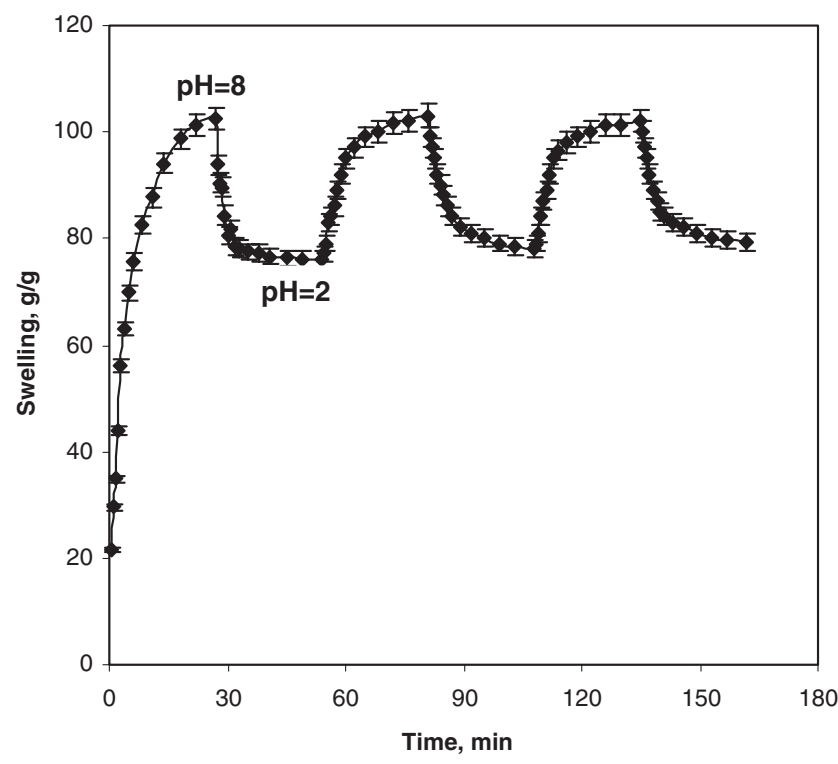

Figure 11. On-off switching behavior as reversible pulsatile swelling $(\mathrm{pH}$ 8.0) and deswelling $(\mathrm{pH} 2.0)$ of the optimized sample. The time interval between the $\mathrm{pH}$ changes was $30 \mathrm{~min}$.

addition, the change in the water absorbency was slight from pH 3 to 8. The poly(AA-co-AMPS) shows the same behavior as can be seen from this figure.

This behavior may be clarified by a buffer action of the carboxylate group with an acid or base, as previously reported by Lee and $\mathrm{Wu}^{32} \mathrm{In}$ an aqueous solution of a low $\mathrm{pH}$, the carboxylate groups on the polymeric chain can turn into carboxylic acid groups. The carboxylic acid groups show neutral electric charge and lead to a reduction of the repulsion between groups on the polymeric chain. Therefore, the electrostatic repulsion of the chains of the polymer decreases, and this leads to a reduction of the water absorbency. At a high $\mathrm{pH}$ value, the carboxylic acid groups on the polymeric chain can turn into sodium carboxylate groups. Consequently, the screening effect of the counter ion on the polyanion chain leads to a reduction in the expansion of the network. Therefore, the water absorbency is reduced. Similar results have been reported in the case of other hydrogel systems. ${ }^{32,33}$

\section{pH-responsiveness Behavior of the Hydrogel}

Since the present hydrogels show different swelling behaviors in various $\mathrm{pH}$ solutions, we investigated the $\mathrm{pH}$ reversibility of these hydrogels in $0.1 \mathrm{M}$ solutions of phosphate buffer with $\mathrm{pH} 2$ and $\mathrm{pH} 8$ (Figure 11). At $\mathrm{pH} 8.0$, the hydrogel swells up to $102 \mathrm{~g} / \mathrm{g}$ due to anion-anion repulsive electrostatic forces, while at $\mathrm{pH} 2.0$, it shrinks within a few minutes due to protonation of carboxylate groups. Since the existence of counter ions in the buffer solutions, the swelling capacity of hydrogel is appreciably decreased. This sharp swelling-deswelling behavior of the hydrogels makes them as suitable candidate for controlled drug delivery systems. Such on-off switching behavior as reversible swelling and deswelling has been reported for other ionic hydrogels. ${ }^{34}$ 


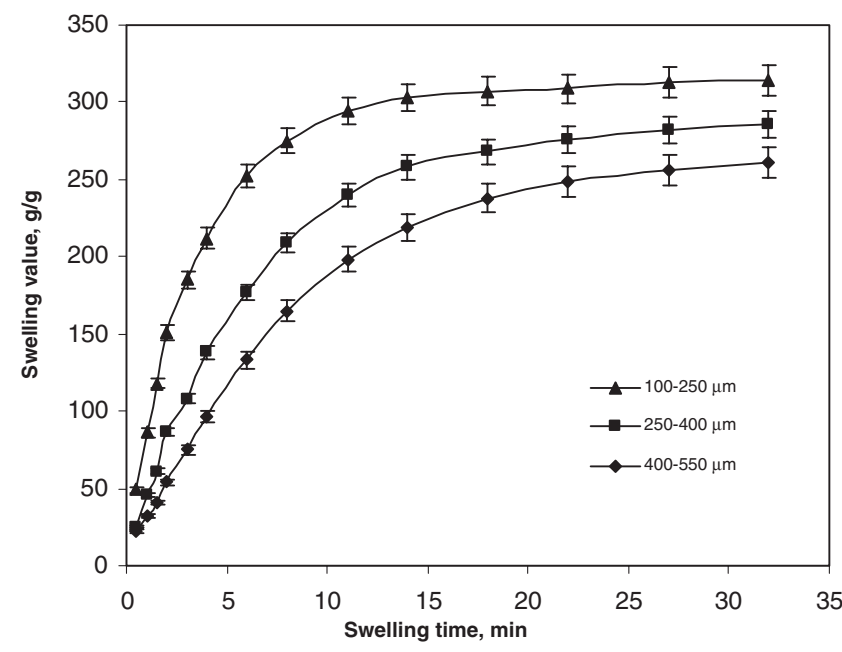

Figure 12. Representative swelling kinetics of the optimized sample with various particle sizes.

\section{Swelling Kinetics}

In practical applications, not only a higher swelling capacity is required, but also a higher swelling rate is needed. Buchholz has suggested that the swelling kinetics for the superabsorbents is significantly influenced by factors such as swelling capacity, size distribution of powder particles, specific size area and composition of polymer. ${ }^{35}$ Figure 12 represents the dynamic swelling behavior of the superabsorbent samples with various particle sizes in water. Initially, the rate of water uptake sharply increases and then begins to level off. The time required to reach the equilibrium swelling capacity was achieved after $\sim 8$ min. A power law behavior is obvious from Figure 12. The data may be well fitted with a Voigt-based equation (Eq. 4): ${ }^{36}$

$$
\mathrm{S}_{\mathrm{t}}=\mathrm{S}_{\mathrm{e}}\left(1-\mathrm{e}^{-\mathrm{t} / \tau}\right)
$$

where $S_{t}(g / g)$ is swelling at time $t, S_{e}$ is equilibrium swelling (power parameter, $\mathrm{g} / \mathrm{g}$ ); $\mathrm{t}$ is time (min) for swelling $\mathrm{S}_{\mathrm{t}}$, and $\tau$ (min) stand for the "rate parameter." The rate parameters for superabsorbent are found to be 5.04, 6.44, and $6.97 \mathrm{~min}$ for superabsorbent with particle sizes of 100-250, $250-400$ and $400-550 \mu \mathrm{m}$, respectively. It is well-known that the swelling kinetics for the superabsorbent polymers is significantly influenced by particle size of the absorbents. ${ }^{37}$ With a lower particle size, a higher rate of water uptake is observed. An increase in the rate of absorption would be expected from the increase in surface area with decreasing particle size of hydrogel.

\section{Water Retention Capacity}

It is important to investigate the water retention ability of a superabsorbent in view of practical application. Figures 13 and 14 show the water retention ability of swollen hydrogel on centrifuging and at different temperatures $\left(60\right.$ and $\left.100{ }^{\circ} \mathrm{C}\right)$. According to the literature ${ }^{38}$ the water in a hydrogel can be classified into bound water, half-bound water, and free water. Compared to bound water and half-bound water, the free water

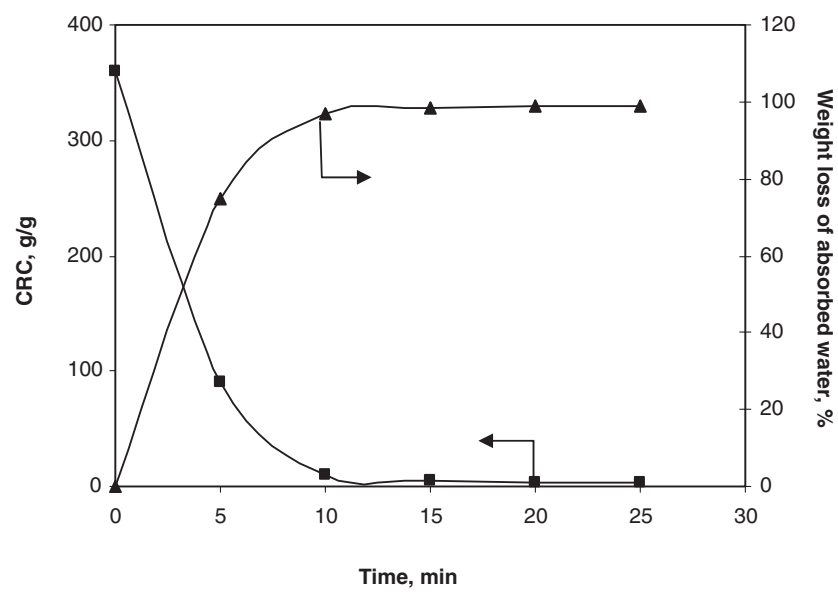

Figure 13. Time dependence of the $\mathrm{CRC}$ values and weight of water lost for optimized sample swollen in distilled water.

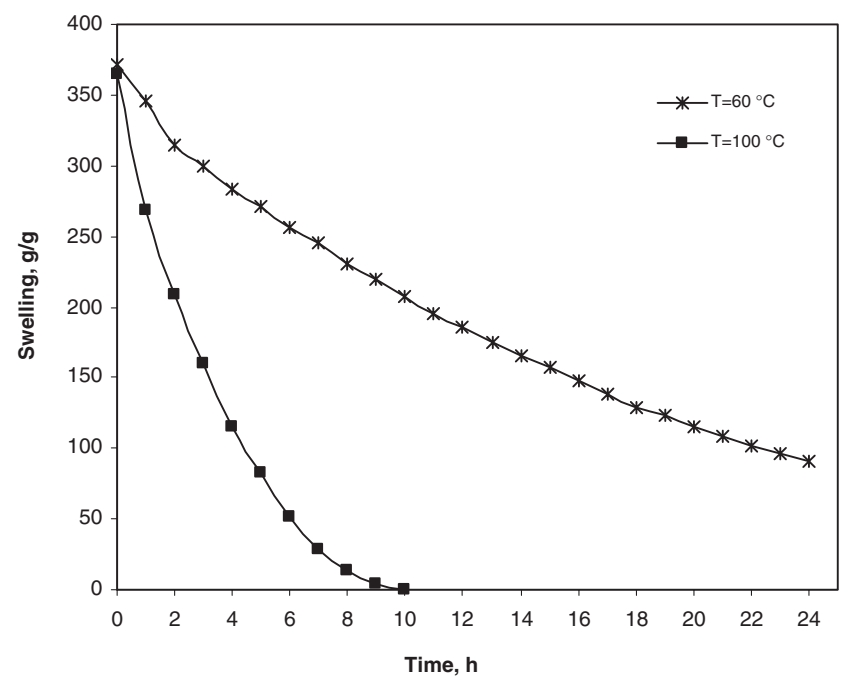

Figure 14. Time dependence of the water retention of the swollen optimized samples at 60 and $100^{\circ} \mathrm{C}$.

in a hydrogel has high mobility and can easily be lost. The percentages of bound water and half-bound water content in swollen gel are related to the number of hydrophilic groups $\left(-\mathrm{SO}_{3} \mathrm{H},-\mathrm{CONH}\right.$, and $\left.-\mathrm{CO}_{2} \mathrm{Na}\right)$ in a unit volume in superabsorbent. As it can be seen from Figure 13, the CRC results indicate that the multifunctional hydrogel can not save water on centrifuging very well in comparison with our previous works, ${ }^{10,15}$ and it may be attributed to higher half-bound and free water content in swollen gels.

It can be seen from Figure 14 that the weight percentage of retained water has a decreasing tendency with prolonging the time both at 60 and at $100^{\circ} \mathrm{C}$. The swollen superabsorbent lost its whole absorbed water approximately within $10 \mathrm{~h}$ at $100^{\circ} \mathrm{C}$ however; it still retains approximately $25 \%$ of its initial water absorbency, even after $24 \mathrm{~h}$ at $60^{\circ} \mathrm{C}$. Consequently, this hydrogel may verify useful for saving water in dry and desert regions. 


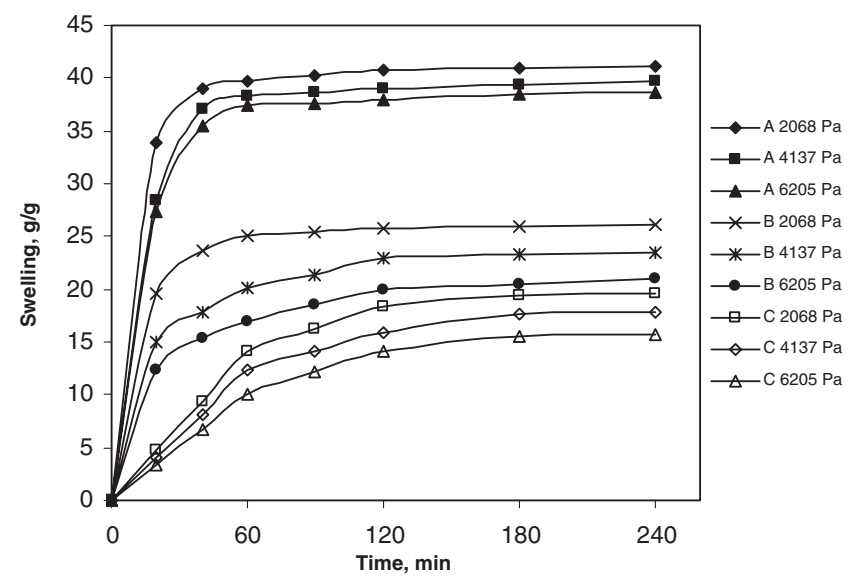

Figure 15. Time dependence of the AUL values for optimized sample (A), poly(AA-co-AMPS) (B) and collagen-g-PAA (C) swollen in saline solution $(\mathrm{NaCl}, 0.15 \mathrm{M})$.

\section{Absorbency under Load}

To determine of the swollen gel strength, AUL is an important factor in the practical application of superabsorbents. The absorbencies measured under different loads are shown in Figure 15. As shown, the minimum time needed for the highest AUL in the case of each load was determined to be $60 \mathrm{~min}$. After this time, the AUL values were unchanged. In addition, the curves unexpectedly exhibit that AUL slightly decreases with increasing the amount of loading which confirm low sensitivity of the hydrogel to different loads. Compared to collagen- $g$-PAA ${ }^{15}$ and poly(AA-co-AMPS), this hydrogel shows much better water absorbency under certain load due to the introduction of the AMPS segment in the former and collagen in the later.

\section{Reswelling Capacity}

After the swollen hydrogel thoroughly loses its absorbed water, the resulting dry sample still retains a good waterabsorbing ability. It can be seen from Figure 16 that sample still retains approximately $80 \%$ of its initial water absorbency, even after repeating the swelling-deswelling-swelling test six times at $100^{\circ} \mathrm{C}$. Figure 16 also indicates that saturated water absorbency decreases with increasing reswelling times. Consequently, this hydrogel may prove useful as recyclable superabsorbent material.

\section{Scanning Electron Microscopy}

Figure 17 showed the scanning electron microscopic pictures of the optimized hydrogel. Although the common methods for drying superporous hydrogels were not used, i.e. vacuum dry or freeze dry, these pictures verify that graft copolymers have a porous structure, where the pores might be induced into the hydrogel by water evaporation resulting from neutralization heat. It is supposed that these pores are the regions of water permeation and interaction sites of external stimuli with the hydrophilic groups of the graft copolymers.

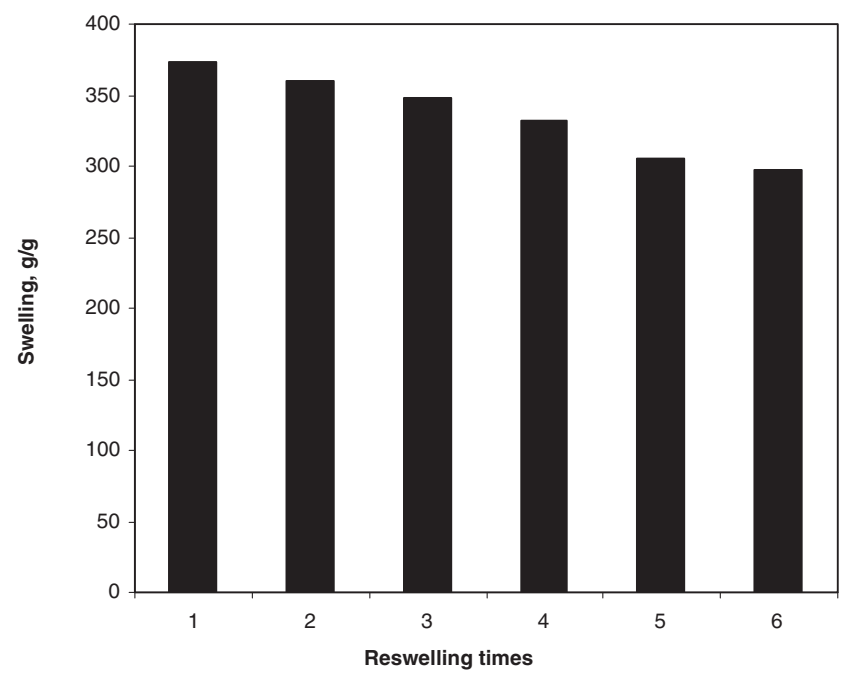

Figure 16. Water absorbency of the optimized superabsorbent in distilled water versus reswelling times.
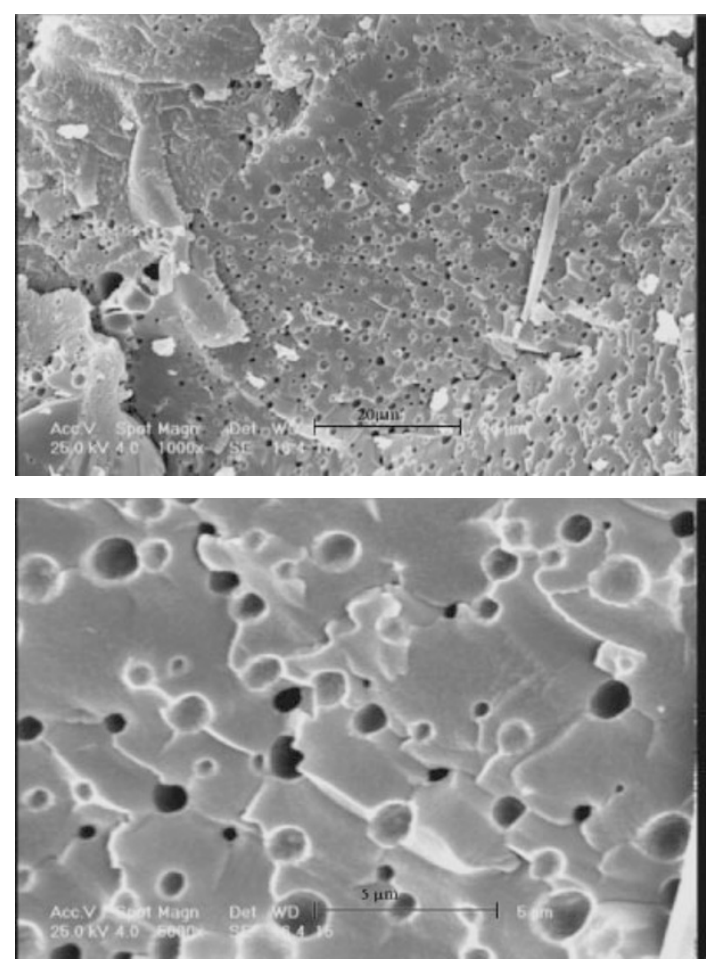

Figure 17. SEM photographs of optimized sample: up $1000 x$, down $5000 x$.

\section{CONCLUSION}

In the present work, we prepared a novel superabsorbent hydrogel by crosslinking graft copolymerization of AMPS/AA onto a hydrolyzed collagen. Swelling measurement of the synthesized hydrogels in different salt solutions showed appreciable swelling capacity, especially in monovalent cation solutions. Also the superabsorbent hydrogels exhibited slight sensitivity to $\mathrm{pH}$ in the range of 3-8. Furthermore, the reversible swelling-deswelling behavior in solutions with 
acidic and basic $\mathrm{pH}$ makes the hydrogels as a candidate for controlled drug delivery systems. Finally, dynamic swelling kinetics of the hydrogels shows that the rate of absorbency is increased with decreasing the particle size of superabsorbing samples. Therefore the prepared hydrogel is a suitable applicant for horticulture and tissue engineering applications due to its superior salt- and $\mathrm{pH}$-resisting properties.

Received: May 14, 2007

Accepted: October 19, 2007

Published: December 4, 2007

\section{REFERENCES}

1. T. Aoki, M. Kawashima, H. Katono, K. Sanui, N. Ogata, T. Okano, and Y. Sakurai, Macromolecules, 27, 947 (1994).

2. Y. Hu, K. Horie, T. Tori, H. Ushiki, and X. C. Tang, Polym. J., 25, 123 (1993).

3. Y. Hirokawa and T. Tanaka, J. Chem. Phys., 81, 6379 (1984).

4. J. Chen and K. Park, J. Controlled Release, 65, 73 (2000).

5. J. Chen and K. Park, Carbohydr. Polym., 41, 259 (2000).

6. T. Gotoh, Y. Nakatani, and S. Sakohara, J. Appl. Polym. Sci., 69, 895 (1998).

7. M. V. Badiger, M. E. McNeil, and N. B. Graham, Biomaterials, 14, 1059 (1993).

8. S. J. Smith and E. J. Lind, U. S. Patent 5399591 (1995).

9. G. R. Mahdavinia, A. Pourjavadi, H. Hosseinzadeh, and M. J. Zohuriaan-Mehr, Eur. Polym. J., 40, 1399 (2004).

10. A. Pourjavadi and M. Kurdtabar, Eup. Polym. J., 43, 877 (2007).

11. J. Chen, H. Park, and K. Park, J. Biomed. Mater. Res., 44, 53 (1999).

12. K. Kabiri and M. J. Zohuriaan-Mehr, Polym. Adv. Technol., 14, 438 (2003).

13. J. Zhang, W. M. Song, L. Zhang, X. M. Xie, and Y. Yang, Petrochem. Technol., 31, 994 (2002).

14. H. Y. Yang, Fine. Chem., 14, 27 (1997).

15. A. Pourjavadi, M. Kurdtabar, G. R. Mahdavinia, and $\mathrm{H}$. Hosseinzadeh, Polym. Bull., 57, 813 (2006).

16. M. J. Ramazani-Harandi, M. J. Zohuriaan-Mehr, A. A. Yousefi,
A. Ershad-Langroudi, and K. Kabiri, Polym. Test., 25, 470 (2006).

17. K. P. Rao, K. T. Joseph, and Y. Nayudamma, Die Makromol. Chem., 175, 729 (1974).

18. K. P. Rao, K. T. Joseph, and Y. Nayudamma, J. Polym. Sci., Part A: Polym. Chem., 9, 3199 (1971).

19. R. M. Silverstein and F. X. Webster, in "Spectrometric Identification of Organic Compounds," 6nd ed., Wiley, New York, 1998.

20. L. B. Peppas and R. S. Harland, "Absorbent Polymer Technology," Elsevier, Amsterdam, 1990.

21. P. J. Flory, "Principles of Polymer Chemistry," Ithaca, Cornell University Press: New York, 1953.

22. N. A. Peppas and A. G. Mikes, "Hydrogels in Medicine and Pharmacy," Vol. 1, CRC Press: Boca Raton, FL, 1986.

23. J. Chen and Y. Zhao, J. Appl. Polym. Sci., 75, 808 (2000).

24. H. Hosseinzadeh, A. Pourjavadi, G. R. Mahdavinia, and M. J. Zohouriaan-Mehr, J. Bioact. Compat. Polym., 20, 47 (2005).

25. S. C. Hsu, T. M. Don, and W. Y. Chiu, Polym. Degrad. Stab., 75, 73 (2002).

26. V. D. Athawale and V. Lele, Starch/Starke, 50, 426 (1998).

27. W. F. Lee and W. Y. Yuan, J. Appl. Polym. Sci., 77, 1760 (2000).

28. J. Branrup and E. H. Immergut, in "Polymer Handbook," 3rd ed., Wiley, New York, 1989.

29. A. Hebeish and J. T. Cuthrie, "The Chemistry and Technology of Cellulosic Copolymers," Springer-Verlag, Berlin, 1981, p 46.

30. G. Pass, G. O. Philips, and D. J. Wedlock, Macromolecules, 10, 197 (1977).

31. M. Tako, S. Toyama, Z. Q. Qi, and E. Yoza, Food Res. Int., 31, 543 (1998).

32. W. F. Lee and R. J. Wu, J. Appl. Polym. Sci., 62, 1099 (1996).

33. W. F. Lee and R. J. Wu, J. Appl. Polym. Sci., 64, 1701 (1997).

34. G. R. Mahdavinia, A. Pourjavadi, and M. J. Zohuriaan-Mehr, Polym. Adv. Technol., 15, 173 (2004).

35. "Superabsorbent Polymers: Science and Technology," F. L. Buchholz and N. A. Peppas, Ed., American Chemical Society, Washington DC, 1994

36. H. Omidian, S. A. Hashemi, P. G. Sammes, and I. Meldrum, Polymer, 39, 6697 (1998).

37. H. Omidian, S. A. Hashemi, P. G. Sammes, and I. Meldrum, Polymer, 40, 1753 (1999).

38. M. Aizawa and S. Suzuki, Bull. Chem. Soc. Jpn., 44, 2967 (1971). 